Portland State University

PDXScholar

Fall 2021

\title{
Addressing and Supporting Mental Health Today: Society-Wide and in Hospital Emergency Departments
}

Kira La Sage

Portland State University

Follow this and additional works at: https://pdxscholar.library.pdx.edu/honorstheses

Part of the Psychiatric and Mental Health Commons, and the Public Health Commons Let us know how access to this document benefits you.

\section{Recommended Citation}

La Sage, Kira, "Addressing and Supporting Mental Health Today: Society-Wide and in Hospital Emergency Departments" (2021). University Honors Theses. Paper 1149.

https://doi.org/10.15760/honors.1179

This Thesis is brought to you for free and open access. It has been accepted for inclusion in University Honors Theses by an authorized administrator of PDXScholar. Please contact us if we can make this document more accessible: pdxscholar@pdx.edu. 


\section{Addressing and Supporting Mental Health Today--Society-Wide and in Hospital Emergency Departments}

by

\section{Kira La Sage}

An undergraduate honors thesis submitted in partial

fulfillment of the

requirements for the degree of

Bachelor of Science

in

University Honors

and

General Science

Thesis Adviser

Joyce Sherpa

Portland State University 
Introduction:

Among the general population in most Westernized countries today, very few issues are as pressing as mental health, or emotional wellness. Many contemporary observers and experts have descriptively labeled the issue approaching epidemic levels. This is the magnitude to which emotional challenges in Western societies have risen.

As we have moved into the 21st Century, the world has seen mental illness and its treatment become an increasingly present issue in society and in emergency departments (ED). In fact, ED's have become the "de facto" destination for primary and acute care of these patients (Larkin et al., 2009). In the United States, "between 2007 and 2016, about 8.4 million (8.3\%) of 100.9 million ED visits nationwide were for psychiatric or substance use-related diagnoses" (Theriault et al., 2020). In other words, roughly 8\%, or one of every twelve, emergency room visits during that time period were not directly connected with medical issues.

The vast majority of emergency department staff in Western hospitals are not trained to appropriately treat mental health or substance-abuse related patients; in fact, as a former medical scribe, I was told more times than I can recall, the emergency department's primary purpose is medical clearance. At the end of the visit to the ED, physicians and other medical professionals utilized one primary criterion: was the patient physically stable enough to be discharged home, or were they in need of more care, leading to hospital admission? I heard these statements from physicians themselves, but also from ED supervisors and the chief medical scribe. How does this priority impact the quality of treatment typically received by those experiencing mental health or psychiatric crises while visiting these emergency departments? Through the use of personal experience and my own research, I will work to answer this question. 
In addition, I will work to elucidate the wealth of evidence testifying to the prevalence of mental health and psychiatric crises in the broader world.

Much of my experience with mental health or psychiatric patients resides in the time I spent working in the ED as a medical scribe. Providing a larger context, beyond just the ED will allow us to see the gravity of this issue.

\section{Background Information:}

Mental illness has been present and recognizable since Ancient Greece, "it was not until 1883 that German psychiatrist Emil Kräpelin (1856-1926) published a comprehensive system of psychological disorders that centered around a pattern of symptoms (i.e., syndrome) suggestive of an underlying physiological cause," (Farreras, 2021, para. 19) that led to these possible disorders. In other words, the treatment, and more or less the understanding of mental illness, has only been a medical focus for 137 years. This means that prior to 1883 , there were vast numbers of people who were not receiving the treatment and care that was needed for them to live and grow as individuals.

In 1952, the first Diagnostic and Statistical Manual (DSM) for mental illness was published. Ingrid Farreras (2021) writes the following about the DSM manual:

It is the 1980 DSM-III version that began a multiaxial classification system that took into account the entire individual rather than just the specific problem behavior. Axes I and II contain the clinical diagnoses, including intellectual disability and personality disorders. Axes III and IV list any relevant medical conditions or psychosocial or environmental stressors, respectively. Axis V provides a global assessment of the individual's level of functioning (para. 20). 
While medicine has come a long way in its recognition, diagnosis, and understanding of mental illness, the one factor medical science can't predict--or effectively address--is that of external influences and their impact on the individual. In our world today, with what feels like greater individual vulnerability than ever before, mental illness is spreading without any widescale effort to address or treat it.

In truth, as the world continues to change, from one generation to the next, and from one societal pressure or unpredictability to the next, recognition and diagnosis seem to become more entrenched as the limitations medicine must cope with when addressing mental illness. Medicine will always have names for conditions; it's the recognition and mitigation of the factors leading to those conditions that has medicine in a continuous "catch-up" mode.

\section{Relevance of the Issue Today:}

Within the last several months, two high-profile examples illustrate the pressures exacerbating, prevalence of, and misinformation surrounding mental illness. First, in Paris, during the French Open Tennis Tournament, one of the "Grand Slam" events in the professional tennis world, in late May and early June of 2021, Naomi Osaka, the world's top-ranked women's tennis player at the time, made the decision to withdraw from the French Tennis Federation's mandated press conferences after each match she would play, citing her need for greater emotional wellness. She spoke, rather briefly, of the debilitating pressure associated with answering questions from garrisons of reporters, that may or may not have anything to do with an athlete's preparation for or response to a match (Goel, 2021, para. 3).

Rather than eliciting immediate support from the tennis community and its governing bodies, her decision invoked a $\$ 15,000$ fine, levied against Osaka (Goel, 2021, para. 1). The fine 
and apparent disregard for her very real concern for wellness quickly led her to withdraw from the tournament completely. She emphasized her need for greater mental health, and to escape the often-unhealthy pressure addressing the media causes for celebrities.

Osaka's decision shocked the women's professional tennis world at the time. This is how "unexpected" her choice was, and how unaware the watching world was of the struggle for emotional wellness that so many young people face while operating under unhealthy levels of stress. The world often falls into the temptation of "idealizing" celebrity lives. What people often overlook is the unending stress that these often-unrealistic expectations place on individuals. Many of these celebrities are youth or young adults, with limited understanding of how to protect or advocate for their own well-being.

The second high profile example came on an even greater stage than one of the major tennis tournaments: Simone Biles, considered by many experts as the greatest women's gymnast of all time, made the decision to withdraw from the Tokyo Summer Olympics women's allaround gymnastics competition in August of 2021, citing her need for emotional wellness. "Biles said, 'At the end of the day, we're human, too, so we have to protect our mind and our body rather than just go out there and do what the world wants us to do"” (Murray, 2021).

As with Naomi Osaka, Simone Biles's decision caught most of the watching world by surprise. Within the national and international gymnastics community there was an apparent ignorance--or disregard--for the toll extreme levels of stress and expectations placed on athletes. For Simone Biles and her reputation as the "greatest of all time," the stress levels were unmanageable.

While many in the media or entertainment industry openly supported Osaka's and Biles's decisions to seek emotional health, many critics labeled these two high profile athletes as people 
ill-prepared for the pressures that all professional athletes face, some going even so far as to label them as cowards.

Offering insight into all athletes at the highest level of accomplishment in their respective sports, Murray (2021) continues with the following:

Approximately one in three elite athletes suffer from anxiety and depression. Our Olympic idols are susceptible to this invisible battle, and so are we. If Biles can demonstrate that it's OK to not be OK on the world's biggest stage in sports, then we can know it is OK for us to not be OK as well (para. 13).

It took two athletes at the pinnacle of their respective sports to turn America's attention to this debilitating issue, but for most people moving into or out of mental health crises, there is no "watching world," waiting to support the individual. Instead, there is a system that is not equipped to handle or help most suffering people find sustainable answers.

Another example of struggles with mental health in the world today can be seen through the Canadian singer and songwriter Justin Bieber. Behind the fame, money, and supposed "happiness" most people perceive in this artist, is and was someone struggling with emotional well-being. In an article by Hannah Yasharoff (2020) from USA Today, she writes about Bieber's recent candidness about his struggles with drug addiction. He reported that he began smoking marijuana around the age of 12 or 13, "later [getting] involved with alcohol, lean (a mixture of codeine cough syrup, soda and hard candy), taking pills, MDMA, psychedelic mushrooms, "everything"” (para.3). His addiction got to the point where his "security and staff would come into [his] room at night to check [his] pulse," (para. 4) to ensure that he was still alive. 
The heart of this addiction was rooted in his unattended mental health issues. Bieber's manager reported that he went through a "dark period" from the ages of 19 to 21 and that he had "gone through a lot in a short life" (Yasharoff, 2020, para. 6). Additionally, Justin's wife, Hailey Bieber, "said she thought his then-undiagnosed 'crippling anxiety' led the young star to self-medicate" (para. 9).

Luckily, Justin has been able to find the resources to improve his mental health and become sober. Unfortunately, other celebrities like Mac Miller and Lil Peep, both American rappers, were not able to find these resources. Both individuals died at far too young an age from drug overdoses that were a result of their struggles with mental health illnesses.

High profile examples bring much-needed attention to the struggles so many members of society face to find mental and emotional wellness. What they cannot do, however, is ensure that any given person on the street, or any given adolescent in a suburban home, or any given student in a public middle or high school, will be able to find resources that may help them navigate the complex, uncertain world of mental health services.

This is the essence of this issue: that most members of society who are struggling to find emotional health, do not know how to or have the internal strength or social support necessary, to find a positive direction for their lives.

From these examples, we clearly see the gravity of this issue. If mental health is not adequately addressed and treated, dire consequences are likely. We see this again and again; with every suicide, with every overdose, with every case of depression. Suicide is already the second leading cause of death for teenagers, ages 13 to 19 (VanOrman et al., 2016). What happens if Western societies don't address the epidemic with sustainable, meaningfully impacting attention 
and resources? How long before this becomes the leading cause of death for people of other ages?

Those may be dire questions or predictions, but the importance of what this paper is examining--and proposing--is, literally, a matter of life and death for far too many members of our next generation of decision makers.

While not all people suffering from some form of mental illness will end up taking their lives, or attempting to, but that does not disregard the struggles these individuals face daily to function productively in their everyday lives. Addressing this issue all begins with finding resources for individuals experiencing mental health crises, and long-term planning. In truth, when an individual experiences a crisis--whether of an emotional or mental health nature or otherwise--they most often find their way into an emergency department--at least in the United States.

Examining this issue just a little closer to home, an article by Mark Harbarger (2019) on Oregonlive.com, revealed some of the enormous challenges at hand when addressing Portland and the entire state of Oregon's mental health needs. "For the past several years, Oregon has had the highest rate of people with mental illness in the country - one in four. It is also one of the worst at providing access to treatment and keeping people in care" (para. 5). Pat Allen, mental health chief of Oregon, "acknowledges the stats and can list the symptoms: Oregon has the highest rate of substance abuse in the country, more people die of overdoses than car crashes, suicide is the second leading cause of death for young people" (para. 7).

The picture is dire--locally and nationally--yet we continue to look for answers. There are examples of help rising and this writing will examine them; but there are also enough remaining challenges that the need continues to exist for everyone with a voice and a concern to advocate. 
If we continue to speak, in whatever forum or outlet we possess, perhaps those with the ability to make a difference will be moved to action.

\section{Personal Anecdotes:}

For the majority of the year of 2020, or when the COVID-19 pandemic began, I worked as a medical scribe in an Emergency Department in the state of Washington. During my time working at this hospital, I encountered many psychiatric and substance-abuse related patients. While the shortcomings of available care were obvious, it was the individuals I witnessed that jumped off the page for me as examples of what this paper addresses.

One specific example of a psychiatric encounter I witnessed happened in the last three months of 2020. During this incident, my physician supervisor and I were presented with an adolescent, who initially complained of abdominal pain. When the physician and I went to the room to speak with the individual and the mother to discover possible causes of the pain, the patient reported that she/he had eaten a cloth bath towel.

Initially, the physician and I were taken by surprise and questioned the patient further. After speaking more in depth, the patient reported that the bath towel had been eaten string by string, until the towel was gone. The patient's mother reported that this was not the first time that this had happened. This case required medical attention, but also psychiatric, in that consuming cloth bath towels is not something exhibiting emotional or psychiatric well-being.

Another example of the challenges connected with treating mental health or psychiatricrelated patients that I encountered during my work in the emergency department, was strictly psychiatric-related. My physician supervisor and I went to visit a new patient we had been assigned to in the psychiatric section of the ED. During our conversation with this individual, the 
patient stated that he/she was being followed by government officials and that she/he needed to speak with someone from the CIA. During this encounter, she/he appeared distressed and disheveled.

This example is a relatively calm encounter I had with a psychiatric patient. Other examples were more violent or hostile secondary to the patient's lack of cooperation and the kind of mental crisis they were experiencing. If a patient was exhibiting violent or aggressive behavior, the provider would order the patient to be chemically or physically restrained. With a physical restraint, the patient would be strapped down to the hospital bed by the individual's wrists and ankles, or a four-point restraint. If a chemical restraint was ordered, the patient would be given some form of sedative to calm them down and eventually cause them to lose consciousness.

As one may imagine, this may not seem like the most immediately beneficial action to take on someone who is experiencing a mental health crisis, but what else can the ED staff do? After all, they are not trained psychiatric professionals; they are medical professionals.

\section{The Effect of the COVID-19 Pandemic:}

The past eighteen months also presents the issue of mental health in correlation to the events of COVID-19. Throughout the pandemic, numerous countries have had periods of complete shut down or isolation, resulting from the "Stay at Home Orders." Given the isolation many have experienced due to these regulations, there are also many articles that have addressed mental health in our world today. The COVID-19 pandemic has also given rise to a dramatic alteration in outpatient mental health care. A vast majority of psychologists, psychiatrists, 
therapists, and other health professionals have moved from in-person appointments to tele-health medicine (Talevi et al., 2020).

Tele-health medicine essentially involves what would typically occur at a regular inperson appointment, but over a Zoom call or Facetime video. Although the care is supposed to be more or less equivalent to in-person treatment, only so much can be done over the phone or through a monitor. The lack of physical contact or interaction has a significant effect on the care these patients receive.

From April, 2020 to September, 2020, I was a recipient of tele-health therapy. I met on a weekly basis with my therapist to receive treatment for mental health. Throughout this time period, my mental health status improved, but it always felt as though something was missing for me. The fact that I could not physically interact with my therapist or actively participate in the activities that would have been conducted in an in-person appointment greatly affected the quality of my treatment, which eventually led to my cessation of therapy.

I understand that the times we live in, with the COVID-19 pandemic influencing all aspects of life, have drastic effects on the treatment mental health patients receive. With this, we also must understand that medical professionals, especially in the ED, are not specifically trained to provide treatment to psychiatric patients. Shirilee Kerrison et al. (2007) go on to discuss the specific care of these patients in terms of ED nurses and how ill-prepared they are to provide effective treatment.

Treatment of Mental Health Patients in the ED in Western Societies:

As previously stated, the emergency department is the "de facto" destination for individuals experiencing acute mental health crises. The issue with this resides in the fact that the 
personnel working within the ED are not trained specifically in how to handle individuals in this mental health state, resulting in ineffective care. Kerrison et al. (2007) writes the following regarding the lack of availability of proper care:

Inappropriate triaging and assessment of patients with acute mental health issues often culminates in an extended length of stay in the ED. These hold-ups are due to delays in review, sedation of patients displaying psychotic or disturbed behavior and limited psychiatric inpatient bed availability (para.1).

This is just one example of how emergency departments are ill-prepared to handle individuals with mental health issues.

Similarly, another article, by Simon Judkins et al. (2019) argues the same issue, but from a different perspective. This article argues that Australia's treatment of mental health is similar to many other countries. Judkins writes the following about his research on Australian emergency departments:

Australian Governments have set a 4-h target for all ED care, but the data show that people presenting to an ED in a mental health crisis are the group most likely to wait more than $24 \mathrm{~h}$ for care. These long waits, seemingly with no end in sight, are harmful for patients and deeply frustrating for clinicians (para.4).

Extended stays in ED's for patients experiencing mental health or psychiatric crises is more the norm than exception. Lisa Creamer (2017) of Boston, Massachusetts NPR station writes on a study that was conducted focusing on ED length of stay in Massachusetts revealed similar findings: "Inside some Massachusetts emergency rooms, patients suffering from mental illness languish for hours, even days, to receive care, while other patients in physical crises experience far shorter ER wait times" (para. 1). In fact, "researchers observed patients with 
mental health issues waited an average of 16.5 to 21.5 hours for an admission or a transfer. Meanwhile, patients with physical health problems spent an average of about four hours inside the ER" (para. 3).

During my work as a medical scribe, I witnessed mental health patients enduring much longer stays in the ED than what appeared to be necessary. Repeatedly during my work, my provider and I would encounter significant numbers of psychiatric patients, most of whom had already been in the ED for hours or days on end. During this extended time in the ED, patients would be seen a handful of times a day by a provider, with each visit being a new provider.

These patients would be cared for by nurses and other medical staff during this time, but by no means would they receive the same level or length of attention as patients in need of immediate physical treatment.

Most often, the reasoning behind mental health patients staying in the ED for so long was that of observation, placement, emergency psychiatric services (EPS) evaluation, etc. For most people examining this issue initially, these reasons appear as fair justification for more time spent in the ED; in reality, mental health professionals agree the reasoning is not justified.

Most emergency care observers agree that no individual should have to stay days on end in a psych ward in the ED, regardless of their condition. This is due to how the psych ward in a typical ED is structured. The psych ward is an area of the ED that is completely secluded from all other areas.

This area houses approximately 8-10 rooms that are set up in a manner much like one would find in a prison. To gain access into the psych ward, one must have an access card, which is given only to persons who work in the ED. There is a set of two doors to enter the psych ward. Once the first door has been opened, the second door cannot be opened until the first door has 
been completely shut and locked. After one has opened the second door, there is a medium-sized room that has access to all the rooms. In that room, there is also a glass window room on the other side where all the nurses, security guards, etc. stand behind to observe the psych patients. Each of the patient rooms has a small window on the door. These rooms provide no access for patients to the outside world, daylight, etc. Spending days on end in this area of the ED does not allow these patients to experience normal day-to-day life interactions that are necessary for adequate human functioning.

Simon Judkins et al. (2019) continues to write about psychiatric patients and their extended periods of stay in the ED with the following:

There are regular instances of patients spending 4-5 days in EDs, with the longest reported time of 176 hours in a recent survey, while their doctor tries to find an appropriate inpatient bed. This is particularly challenging when caring for young people and people outside metropolitan areas (para. 4).

As a result of this extended time in the ED, mental health patients are more likely to leave AMA (against medical advice) or prior to treatment. In addition, longer ED stays and prolonged treatment have led to increased agitation and resulting aggression in mental health patients. Secondary to this aggression, patients are often forced to be restrained (through physical or chemical means), a condition most professionals agree would likely not have been needed had there been in place a more efficient treatment plan and time of care (Judkins et al., 2019, para. 5).

Not only that, on average, most emergency departments run at maximum capacity in terms of their mental health unit. In other words, this "ensures that those in acute crisis and needing inpatient care are forced to wait in the ED” (Judkins et al., 2019, para. 6). 
Another article from Margaret Dolan et al. (2011) of the American Academy of Pediatrics goes on to argue that not only are mental health patients not handled correctly within emergency departments, but the issue is continuing to worsen, with greater numbers of mental health patients each year. In fact, “A 2008 report from the Centers for Disease Control and Prevention noted that ED visits increased 32\% from 1996 to 2006, whereas the number of EDs decreased by 5\%" (pg. 2). This juxtaposition of needs and resources begs the question: "What more can be done to better address and meet the care of these patients in the ED and provide resources for long-term care of these patients?"

Thus far, we have investigated various ways that mental health patients have been poorly served and treated in emergency departments throughout the world. Given these conditions, many may ask, "How is this relevant to me if I have never been in a state of mental health crisis?"

This is a valid question, but many, perhaps most, fail to understand or acknowledge that suicide, which is potentially the direst of all mental health crises, has "become the secondleading cause of death among teenagers in the United States, surpassing homicide deaths, which dropped to third on the list" (VanOrman, 2016, para. 1). In addition, "The suicide rate among persons aged 10-24 was stable from 2000 to 2007, and then increased 56\% between 2007 (6.8 per 100,000) and 2017 (10.6 per 100,000)" (Curtin, 2019, para. 3). With any other public health condition, citizens from all walks of life would be compelled to participate in finding a solution if they were to see a $56 \%$ increase in cases during a 10 -year period. Suicide and suicidal ideation may not be applicable to every individual in this world, but the fact that the second leading cause of death for teenagers is suicide should be salient to everyone. 
Secondary to this lack of awareness or concern for mental illnesses, the increase in suicide and suicide attempts has also led to an increase in individuals needing medical attention, further taxing the limited resources emergency departments consistently function with. Emergency department personnel provide the best care they can with the resources they have; unfortunately, those experiencing mental health crises do not fit neatly within emergency department capacities or standard operating procedures.

\section{Possible Solutions:}

Effectively addressing the rapid increase in mental health challenges so many people face all starts with the treatment and care they receive. I have already shared that one of the primary outlets for identifying the care or treatment these individuals need is through the ED. Without the availability of proper long-term care planning, how can these people expect to avoid repeat visits to the ED in the foreseeable future when they are experiencing a mental health crisis that was not properly handled during the first encounter?

Ingrid Farreras (2020) writes that the "progress in the treatment of mental illness necessarily implies improvements in the diagnosis of mental illness" (para.19). In other words, if medical professionals are able to diagnose and understand the symptoms they are being presented with from their patients, they will then be able to better care for them.

Farreras (2020) also writes that "a standardized diagnostic classification system with agreed-upon definitions of psychological disorders creates a shared language among mentalhealth providers and aids in clinical research" (para. 19). 
While diagnoses and treatments have come a long way from the horror stories of Victorian society, there are still too many people searching for sustainable answers to how we can better serve those experiencing mental health challenges.

All in all, the most obvious solution to improving mental health issues in our world today would be providing the appropriate outpatient and treatment programs for patients. This is an ideal but as with so many provisions not considered "essential” by greater society, it hasn't yet happened and leaves people vulnerable during a time of crisis or emergency.

The Unity Center for Behavioral Health by Legacy Emanuel in Portland, Oregon is one such resource seeking to address this solution. This center is a "24-hour behavioral and mental health services center located in the greater Portland metropolitan area" ("Unity Center," 2021, para. 1). The center provides "immediate psychiatric care and a path to recovery for people experiencing a mental health crisis" (para. 1). This center is staffed with psychiatric professionals who provide care in the areas of "crisis stabilization, crisis intervention, medication management, crisis counseling, social work and family and peer support” (para. 2). In other words, the center is laid out in a way similar to that of an ED, but specifically for mental health patients.

Although this is a wonderful solution to poor health care of mental health patients within the ED, there are a couple limitations to the Unity Center. One of those is that this center is strictly for patients who are 18 years of age or older, completely excluding adolescents in crisis. Another limitation of this solution is that The Unity Center is the "first collaborative medical initiative of its kind in Oregon and Southwest Washington" ("Unity Center," 2021). In other words, this is the first mental health center of its kind in the Portland-Vancouver-Hillsboro 
metropolitan area, serving approximately 2.5 million people, as of 2020 ("Portland," 2021). By no means is this center equipped to serve a population of this size.

Overall, The Unity Center is a great solution to serving people experiencing mental health or psychiatric crises, but there are far too few of them. Construction and operation of these buildings requires financial stability, which often stems from government funding, grants, donations, etc., all of which can be inconsistent streams. More awareness of this issue and greater intentionality from community leaders can bring attention to this matter, hopefully encouraging broader, more sustainable sources of funding for more of these centers.

Another possible solution for those experiencing a mental health crisis can be found two hours to the south of Portland: in Eugene, Oregon. In response to the George Floyd killing in May, 2020, many concerned parties began searching for some way to remove police officers from potentially explosive situations, where psychiatric or mental health challenges exist (Gerety, 2020).

As the searching for solutions continued, one model, actually in existence since 1989, began to emerge: CAHOOTS (Crisis Assistance Helping Out On The Streets). CAHOOTS does the following:

The program mobilizes two-person teams consisting of a medic (a nurse, paramedic, or EMT) and a crisis worker who has substantial training and experience in the mental health field. The CAHOOTS teams deal with a wide range of mental health-related crises, including conflict resolution, welfare checks, substance abuse, suicide threats, and more, relying on trauma-informed de-escalation and harm reduction techniques. CAHOOTS staff are not law enforcement officers and do not carry weapons; their training and experience are 
the tools they use to ensure a non-violent resolution of crisis situations ("What is," 2020).

"In 2017, the CAHOOTS teams answered 17\% of the Eugene Police Department's overall call volume. The program saves the city of Eugene an estimated $\$ 8.5$ million in public safety spending annually" ("What is," 2020). Allowing mental health professionals to be the first point of contact for those experiencing crisis is a major step in the direction of preventing much of the police violence we see in our country today.

For those committed to finding sustainable solutions to what has become an epidemic of mental health challenges, there is also wisdom in looking at what other nations are considering. One such country exploring how industry, government, mental health groups, and service users can work together is the United Kingdom. The Rand Corporation Europe is exploring what is currently happening in the UK to bring these difference makers together (Van Stolk et al., 2016).

Secondary to the issue of differing mental health problems and needs among people, different services and groups must work together or be incorporated to find "appropriate solutions for those with differing mental health problems and needs" (Van Stolk et al., 2016). Van Stolk et al. (2016) continues with the following:

The use of technology to deliver mental health services is one area of particular interest and is being explored in more detail by the government. The overall aim is helping people get access to the mix of services they need, while also helping them get back to or stay in work (para. 10).

Another solution suggested comes in the form of state-mandated actions, especially in light of the impact COVID-19 has had on our collective mental well-being. One organization proposing, sponsoring, and working toward policy change is the United States of Care. One of 
this organization's key recommendations for a nationwide approach to effectively addressing our growing mental health epidemic is the following: "States should require insurers to cover mental health and substance use disorder care before deductibles and without referrals, and radically expand access to medication, emergency overdose products, and other evidence-based treatment and recovery support services" (Hagan et al., 2020). With this statement, clearly the expectation is that a sustainable solution to society's expanding mental health epidemic cannot exist without participation from state and federal legislators.

\section{Summary:}

There is no single silver bullet that will effectively and sustainably reduce our everincreasing mental health epidemic. People and the factors contributing to the challenges we face are simply too diverse and unpredictable for that to happen. The hope is that this paper has made that reality clear.

But if society can see enough relevant, difference-making organizations and entities working together in something resembling a similar direction, offering solutions and, just as importantly, hope, to those experiencing crisis, we may begin to see a visible impact in the lives of those who need it most. Society needs to see organizations such as CAHOOTS or The Unity Center meaningfully impacting lives. If mass media outlets begin to play a crucial role, positively communicating these organizations' difference-making efforts, society may then begin to see enough pieces falling into place, positively impacting what continues to be a staggering number of individuals suffering from crisis. 


\section{References}

Creamer, L. (2017, January 05). Study: Patients With Mental Illnesses Wait Significantly Longer Inside Mass. Emergency Rooms. Retrieved from https://www.wbur.org/news/2017/01/05/study-mental-illness-er-waits

Curtin, S. C., \& Heron, M. (2019, October). Death Rates Due to Suicide and Homicide Among Persons Aged 10-24: United States, 2000-2017. Retrieved from https://www.cdc.gov/nchs/data/databriefs/db352-h.pdf

Dolan, M., MD, \& Fein, J., MD. (2011). Technical Report—Pediatric and Adolescent Mental Health Emergencies in the Emergency Medical Services System.

Farreras, I. G. (2021). History of Mental Illness. Retrieved from https://nobaproject.com/modules/history-of-mental-illness

Gerety, R. M. (2020, December 28). An Alternative to Police That Police Can Get Behind. Retrieved from https://www.theatlantic.com/politics/archive/2020/12/cahoots-programmay-reduce-likelihood-of-police-violence/617477/.

Goel, V. R. (2021, May 31). Naomi Osaka fined \$15,000 and threatened with suspension for avoiding media at French Open. Retrieved November 11, 2021, from https://www.cbsnews.com/news/naomi-osaka-french-open-fined-media/

Hagan, L., Ibarra, O., \& Kunau, R. (2020, October 8). Healing Our Nation: State-Based Solutions For Connecting People to Mental Health Care and Addiction Recovery Services. Retrieved from https://unitedstatesofcare.org/healing-our-nation-mental-healthcare/. 
Harbarger, M. (2019, December 15). Oregon's mental health system is broken. This reformer thinks he can fix it. Retrieved from https://www.oregonlive.com/health/2019/12/oregonsmental-health-system-is-broken-can-the-reformer-hired-to-fix-it-succeed.html

Judkins, S., Fatovich, D., Ballenden, N., \& Maher, H. (2019). Mental health patients in emergency departments are suffering: The national failure and shame of the current system. A report on the Australasian College for Emergency Medicine's Mental Health in the Emergency Department Summit. Retrieved from https://journals-sagepubcom.proxy.lib.pdx.edu/doi/pdf/10.1177/1039856219852282

Kerrison, S. A., \& Chapman, R. (2007, January 02). What general emergency nurses want to know about mental health patients presenting to their emergency department. Retrieved from https://www.sciencedirect.com/science/article/abs/pii/S096523020600066X

Larkin, G., Beautrais, A., Spirito, A., \& Kirrane, B. (2009). Mental Health and Emergency Medicine:A Research Agenda. Retrieved from https://onlinelibrary.wiley.com/doi/epdf/10.1111/j.1553-2712.2009.00545.x

Murray, H. (2021, July 30). What Simones Step Back Teaches Us. Retrieved from https://athletesinaction.org/articles/what-simones-step-back-teachesus/?gclid=Cj0KCQjwnoqLBhD4ARIsAL5JedIxIy8wni6_2JsuMfPp00LWsKJyzNaOUk3 etRUOX3tbecGs1z3FvX4aAvAIEALw_wcB

Portland metro area population 2020. (2021, April). Retrieved from https://www.statista.com/statistics/815306/portland-metro-area-population/

Talevi, D., Socci, V., Carai, M., Carnaghi, G., Faleri, S., Trebbi, E., . . Pacitti, F. (2020, May 01). Mental health outcomes of the Covid-19 pandemic. Retrieved from https://www.rivistadipsichiatria.it/archivio/3382/articoli/33569/ 
Theriault, K., Rosenheck, R., \& Rhee, T. (2020). Increasing Emergency Department Visits for Mental Health Conditions in the United States. Retrieved from https://pubmed.ncbi.nlm.nih.gov/32726001/

Unity Center for Behavioral Health - Portland Oregon. (2021, November 05). Retrieved from https://www.unityhealthcenter.org/

Van Stolk, C., \& Hofman, J. (2016, October 19). Outside-the-Box Solutions to Mental Health Problems. Retrieved from https://www.rand.org/blog/2016/10/thinking-outside-the-boxto-find-solutions-to-mental.html

VanOrman, A., \& Jarosz, B. (2016, June 9). Suicide Replaces Homicide as Second-Leading Cause of Death Among U.S. Teenagers. Retrieved from https://www.prb.org/resources/suicide-replaces-homicide-as-second-leading-cause-ofdeath-among-u-s-teenagers/

What is CAHOOTS? (2020, October 29). Retrieved from https://whitebirdclinic.org/what-iscahoots/

Yasharoff, H. (2020, February 04). Justin Bieber gets candid about past drug addiction, getting sober: I 'felt like I was dying'. Retrieved from https://www.usatoday.com/story/entertainment/celebrities/2020/02/04/justin-bieber-drugaddiction-detailed-waking-up-popping-pills-getting-sober/4653541002/ 